\title{
Review Article \\ The Impact of Neural Stem Cell Biology on CNS Carcinogenesis and Tumor Types
}

\author{
K. M. Kurian \\ Department of Neuropathology, Frenchay Hospital, Bristol BS16 1LE, UK \\ Correspondence should be addressed to K. M. Kurian, kathreena.kurian@doctors.org.uk
}

Received 13 January 2011; Accepted 14 March 2011

Academic Editor: Tarik Tihan

Copyright $\odot 2011$ K. M. Kurian. This is an open access article distributed under the Creative Commons Attribution License, which permits unrestricted use, distribution, and reproduction in any medium, provided the original work is properly cited.

The incidence of gliomas is on the increase, according to epidemiological data. This increase is a conundrum because the brain is in a privileged protected site behind the blood-brain barrier, and therefore partially buffered from environmental factors. In addition the brain also has a very low proliferative potential compared with other parts of the body. Recent advances in neural stem cell biology have impacted on our understanding of CNS carcinogenesis and tumor types. This article considers the cancer stem cell theory with regard to CNS cancers, whether CNS tumors arise from human neural stem cells and whether glioma stem cells can be reprogrammed.

\section{Introduction}

Epidemiological data suggests that the incidence of gliomas-the most common form of intrinsic brain tumour-is rising [1-3]. This is surprising, because the brain is partially protected from the environment factors by the blood-brain barrier and has a low proliferative potential compared with other organs. Recent advances from the stem-cell biology field have impacted on our understanding of CNS carcinogenesis and tumor types [4-7]. This paper considers the evidence for the cancer stem cell theory, whether CNS tumours arise from human neural stem cells and whether glioma stem cells can be reprogrammed.

\section{Cancer Stem-Cell Theory}

Normal human neural stem cells are thought to reside within the brain mostly in the subventricular zone (SVZ) lining the lateral ventricles and within the dentate gyrus of the hippocampus $[8,9]$. These stem cells persist throughout adulthood into old age and may divide symmetrically for self-renewal and asymmetrically to produce neurons, astrocytes, and oligodendrocytes [10]. By comparison, brain cancer or glioma stem cells are a population within a glioma that can divide infinitely, have the capacity to show neuronal, astrocytic, and oligodendroglial differentiation and can recapitulate the whole tumour when transplanted into the brain of a nude mouse [11-13]. Whether brain cancer stem cells actually develop from preexisting human neural stem cells or represent cells which reacquire a stemlike state as a by product of tumorigenesis or in vitro culture conditions remains controversial [11-13]. Brain cancer/glioma stem cells are of great interest, because they may represent the population of cells within a tumour that may be resistant to therapy and responsible for tumour relapse.

Cancer stem cells, were originally described in acute myeloid leukaemia and in haematological malignancies and subsequently in many solid tumours $[4,6,7]$. Brain cancer stem cells, also termed brain tumour-initiating cells were first described by groups who used CD133 to isolate a population of brain tumour initiating or stem cells within glioblastoma, the most aggressive primary brain tumour $[12,14,15]$. The precise function of CD133, also known as prominin, remains unclear; however, it was originally shown to be a haemopoietic stem-cell marker [10]. Original papers suggested that CD133-positive stem-like cells were the only subpopulation of cells within the glioblastoma that were capable of producing tumours when transplanted into the brain of immunodeficient mice [12, 14]. More recent studies suggest that this may not always be the case and that CD133 is not a specific marker for brain tumour-initiating 
cells or cancer stem-cells within glioma [15]. Therefore many experimental difficulties still revolve around the lack of specific glioma stem cell markers.

The question whether there is a universal glioma cancer stem cell or whether different subtypes of glioma contain different stem cells remains unanswered. Gilbertston's group suggest that the stem cell may vary according to the nature of the original tumour [16]. He has shown that subtypes of a different type of glial tumour (ependymoma) may derive from radial glia at different locations at different stages of development in the nervous system. It is possible that radial glia may represent the stem cell of ependymomas [17]. These cells express CD133, RC2, and nestin, which are present on radial glia and human neural stem cells.

In addition glioma stem cells are dependent on their microenvironment in order to maintain stem-cell properties. There is evidence to suggest that endothelial cells interact and secrete factors in vitro that maintain a stem-like state [17]. Increasing the number of endothelial cells expands the population of self-renewing cells and their tumorigenic properties. It is therefore possible that stem-like cells survive within a vascular niche [17].

\section{Do CNS Tumours Arise from Human Neural Stem Cells?}

It is difficult to determine whether CNS tumours arise from human neural stem cells because of the difficulties targeting these cells and the lack of robust stem-cell markers. Recent work suggests that different combinations of genetic mutations in the adult mouse subventricular zone determine different brain tumour phenotypes $[18,19]$. The SVZ is a well-described niche containing stem cells (type B cells), transient amplifying precursors which derive from them (type C cells), and neuroblasts (type A cells) [20, 21]. Many studies use a GFAP-cre-mediated approach in transgenic mice to target type B stem cells expressing GFAP and subsequent progenitors expressing Nestin during development. One intriguing study has shown that stimulation of the PDGFR alpha expressing B-type neural stem cells induces the formation of hyperplasia-resembling oligodendrogliomas next to the SVZ [22], which regresses after the withdrawal of the growth factor. Similar approaches have shown that the inactivation of various combinations of other tumour suppressor genes forms malignant astrocytomas in the developing mouse brain SVZ. The inactivation of $\mathrm{Nf1}$ and p53 in neural stem/progenitor cells of the SVZ and the inactivation of PTEN and p53 in progenitor cells result in the formation of malignant astrocytomas [23, 24]. Other studies have shown that the activation of oncogenes Ras and Akt in nestin-expressing progenitors (but not in GFAP-expressing SVZ stem cells) induces glioblastoma [25]. Similarly, nestin-expressing GFAP-negative progenitor cells deficient in INK4a/ARF and Bmil, isolated in vitro, can give rise to low-grade diffuse astrocytomas [26].

Experiments in the adult SVZ have used a similar cre-lox method in transgenic mice. The inactivation of combinations of Nf1 and p53, or Nf1, p53 and PTEN, in Nestin expressing cells results in the formation of malignant gliomas [27, 28]. An interesting study combining the inactivation of $\mathrm{Rb}$ and p53 in GFAP-expressing cells of the adult subventricular zone resulted in the formation of primitive neuroectodermal tumours (PNET) rather than gliomas, suggesting that the inactivation of $\mathrm{Rb}$ may be key in determining this tumour phenotype [17].

Although these experimental models are compelling evidence for the development of brain cancers from neural stem cells, there are several reports indicating that transformed mature astrocytes outside the SVZ can form gliomas given appropriate mutations [29-33]. This is coupled with the clinical observation of glioma occurrence in locations outside the traditional stem-cell compartments, and therefore the jury is still out on whether all CNS tumors arise from human neural stem cells.

\section{Can We Reprogramme Glioma Stem Cells?}

A major conceptual advance in stem-cell biology field revolves around the work by Takahashi et al. [34]. Yanamaka "reprogrammed" mature skin fibroblasts into induced pluripotent stem cells, commonly abbreviated as iPS cells or iPSCs with four factors: Oct4, klf4, sox 2, and c-myc using a retroviral aproach [34]. These iPS cells are similar to natural pluripotent stem cells, such as embryonic stem cells because they have the potential to be differentiated into different cell types such as nerve or cardiac cells. This advance theoretically allows researchers to obtain pluripotent stem cells from skin or other mature tissues without the controversial use of embryos. It also avoids immune rejection because the cells could be derived entirely from the individual patient to be treated.

More fundamentally, it demonstrates the influence of epigenetics in deciding the phenotype of an individual cell, and raises the possibility that epigenetics could be used to alter cell fate. Initial concerns about the risk of malignancy in reprogrammed human neural stem cells have revolved around the use of c-myc and viral transduction techniques. These have been addressed by using alternative techniques including the 2iIPS system [35], piggy bac transposons [36] and protein based approaches $[37,38]$. In the CNS tumour field it has been shown both in vivo and in vitro that it is possible to make certain types of glioma-initiating stem cells differentiate into neuronal type cells using manipulation of the Bone Morphogenetic Protein (BMP) pathway, which is involved in differentiation of human embryonic stem cells to neural stem cells $[39,40]$. These studies demonstrated a major differentiation block in a subset of glioblastoma is caused by the Polycomb repressor complex-(PRC-) mediated epigenetic silencing of the BMPR1B promoter analogous to early embryonic neural stem cells.

Very recent work (Stricker et al., in press) has shown that direct reprogramming of the glioblastoma epigenome restores developmental potential but does not efficiently suppress proliferation [41]. This fundamental study uses a reprogramming approach to convert glioblastoma into immature teratoma. 


\section{Conclusions}

In conclusion, the cancer stem theory predicts that not all tumour cells are equal. Although we cannot be certain about the precise cell of origin of gliomas, we may have the ability to control them to a certain degree using epigenetic means. This represents a major conceptual advance in the field, but it is still contraversial. Major new insights into cancer stem cells will hopefully direct a new era of patient-specific combined molecular therapies.

\section{References}

[1] K. R. Hess, K. R. Boglio, and M. L. Bondy, "Adult glioma incidence trends in the United States, 1977-2000," Cancer, vol. 101, no. 10, pp. 2293-2299, 2004.

[2] K. M. Kurian, "Recent advances in glial tumours," ANCR, vol. 8, no. 6, pp. 24-26, 2009.

[3] P. Kleihues and W. K. Cavenee, "WHO Classification of Tumours of the Nervous System," 2007.

[4] D. Bonnet and J. E. Dick, "Human acute myeloid leukaemia is organized as a hierarchy that originates from a primitive hemapoetic stem cell," Nature Medicine, vol. 3, pp. 730-737, 1997.

[5] C. D. Stiles and D. H. Rowitch, "Glioma stem cells: a midterm exam," Neuron, vol. 58, no. 6, pp. 832-846, 2008.

[6] T. Reya, S. J. Morrison, M. F. Clarke, and I. L. Weissman, "Stem cells, cancer, and cancer stem cells," Nature, vol. 414, no. 6859, pp. 105-111, 2001.

[7] B. T. Tan, C. Y. Park, L. E. Ailles, and I. L. Weissman, "The cancer stem cell hypothesis: a work in progress," Laboratory Investigation, vol. 86, no. 12, pp. 1203-1207, 2006.

[8] R. McKay, "Stem cells in the central nervous system," Science, vol. 276, no. 5309, pp. 66-71, 1997.

[9] S. M. Pollard, L. Conti, Y. Sun, D. Goffredo, and A. Smith, "Adherent neural stem (NS) cells from fetal and adult forebrain," Cerebral Cortex, vol. 16, pp. 112-120, 2006.

[10] N. Uchida, D. W. Buck, D. He et al., "Direct isolation of human central nervous system stem cells," Proceedings of the National Academy of Sciences of the United States of America, vol. 97, no. 26, pp. 14720-14725, 2000.

[11] T. N. Ignatova, V. G. Kukekov, E. D. Laywell et al., "Human cortical glial tumors contain neural stem-like cells expressing astroglial and neuronal markers in vitro," GLIA, vol. 39, no. 3, pp. 193-206, 2002.

[12] R. Galli, E. Binda, U. Orfanelli et al., "Isolation and characterisation of tumourigenic stem-like neural precursors from human glioblastoma," Cancer Research, vol. 64, pp. 7011$7021,2004$.

[13] H. D. Hemmati, I. Nakano, J. A. Lazareff et al., "Cancerous stem cells can arise from pediatric brain tumors," Proceedings of the National Academy of Sciences of the United States of America, vol. 100, no. 25, pp. 15178-15183, 2003.

[14] S. K. Singh, I. D. Clarke, M. Teraski et al., "Identification of a cancer a stem cell in human brain tumours ," Cancer Research, vol. 63 , pp. 5821-5828, 2003.

[15] K. M. Joo, S. Y. Kim, X. Jin et al., "Clinical and biological implications of CD133-positive and CD133-negative cells in glioblastomas," Laboratory Investigation, vol. 88, no. 8, pp. 808-815, 2008.

[16] M. D. Taylor, H. Poppleton, C. Fuller et al., "Radial glia cells are candidate stem cells of ependymoma," Cancer Cell, vol. 8, no. 4, pp. 323-335, 2005.
[17] R. J. Gilbertson and J. N. Rich, "Making a tumour's bed: glioblastoma stem cells and the vascular niche," Nature Reviews Cancer, vol. 7, no. 10, pp. 733-736, 2007.

[18] T. S. Jacques, A. Swales, M. J. Brzozowski et al., "Combinations of genetic mutations in the adult neural stem cell compartment determine brain tumour phenotypes," The EMBO Journal, vol. 29, pp. 222-235, 2010.

[19] T. G. Oliver and R. J. Wechsler-Reya, "Getting at the root and stem of brain tumors," Neuron, vol. 42, no. 6, pp. 885-888, 2004.

[20] N. Sanai, A. Alvarez-Buylla, and M. S. Berger, "Mechanisms of disease: neural stem cells and the origin of gliomas," New England Journal of Medicine, vol. 353, no. 8, pp. 811-822, 2005.

[21] F. Doetsch, I. Caille, D. A. Lim, J. M. Garcia-Verdugo, and A. Alvarez-Buylla, "Subventricular zone astrocytes are neural stem cells in the adult mammalian brain," Cell, vol. 97 , no. 6 , pp. 703-716, 1999.

[22] E. L. Jackson, J. M. Garcia-Verdugo, S. Gil-Perotin et al., "PDGFR alpha-positive B cells are neural stem cells in the adult SVZ that form glioma-like growths in response to increased PDGF signalling," Neuron, vol. 51, no. 2, pp. 187199, 2006.

[23] H. Zheng, H. Ying, H. Yan et al., "p53 and Pten control neural and glioma stem/progenitor cell renewal and differentiation," Nature, vol. 455, no. 7216, pp. 1129-1133, 2008.

[24] Y. Zhu, F. Guignard, D. Zhao et al., "Early inactivation of p53 tumor suppressor gene cooperating with NF1 loss induces malignant astrocytoma," Cancer Cell, vol. 8, pp. 119-130, 2005.

[25] E. C. Holland, J. Celestino, C. Dai, L. Schaefer, R. E. Sawaya, and G. N. Fuller, "Combined activation of Ras and Akt in neural progenitors induces glioblastoma formation in mice," Nature Genetics, vol. 25, no. 1, pp. 55-57, 2000.

[26] S. W. M. Bruggeman, D. Hulsman, E. Tanger et al., "Bmi1 controls tumor development in an Ink4a/Arf-independent manner in a mouse model for glioma," Cancer Cell, vol. 12, no. 4, pp. 328-341, 2007.

[27] S. Alcantara Llaguno, J. Chen, C. H. Kwon et al., "Malignant astrocytomas originate from neural stem/progenitor cells in a somatic tumor suppressor mouse model," Cancer Cell, vol. 15, no. 1, pp. 45-56, 2009.

[28] Y. Wang, J. Yang, H. Zheng et al., "Expression of mutant p53 proteins implicates a lineage relationship between neural stem cells and malignant astrocytic glioma in a murine model," Cancer Cell, vol. 15, no. 6, pp. 514-526, 2009.

[29] R. M. Bachoo, E. A. Maher, K. L. Ligon et al., "Epidermal growth factor receptor and Ink4a/Arf: convergent mechanisms governing terminal differentiation and transformation along the neural stem cell to astrocyte axis," Cancer Cell, vol. 1, no. 3, pp. 269-277, 2002.

[30] H. Ding, L. Roncari, P. Shannon et al., "Astrocyte-specific expression of activated p21-ras results in malignant astrocytoma formation in a transgenic mouse model of human gliomas," Cancer Research, vol. 61, no. 9, pp. 3826-3836, 2001.

[31] E. C. Holland, W. P. Hively, V. Gallo, and H. E. Varmus, "Modeling mutations in the G1 arrest pathway in human gliomas: overexpression of CDK4 but not loss of INK4a-ARF induces hyperploidy in cultured mouse astrocytes," Genes and Development, vol. 12, no. 23, pp. 3644-3649, 1998.

[32] L. Uhrbom, M. Kastemar, F. K. Johansson, B. Westermark, and E. C. Holland, "Cell type-specific tumor suppression by Ink4a and Arf in kras-induced mouse gliomagenesis," Cancer Research, vol. 65, no. 6, pp. 2065-2069, 2005. 
[33] A. Xiao, C. Yin, C. Yang, A. Di Cristofano, P. P. Pandolfi, and T. Van Dyke, "Somatic induction of Pten loss in a preclinical astrocytoma model reveals major roles in disease progression and avenues for target discovery and validation," Cancer Research, vol. 65, no. 12, pp. 5172-5180, 2005.

[34] K. Takahashi, K. Tanabe, M. Ohnuki et al., "Induction of pluripotent stem cells from adult human fibroblasts by defined factors," Cell, vol. 131, no. 5, pp. 861-872, 2007.

[35] J. Silva, O. Barrandon, J. Nichols, J. Kawaguchi, T. W. Theunissen, and A. Smith, "Promotion of reprogramming to ground state pluripotency by signal inhibition," PLoS Biology, vol. 6, no. 10, Article ID e253, pp. 2237-2247, 2008.

[36] K. Woltjen, I. P. Michael, P. Mohseni et al., "piggyBac transposition reprograms fibroblasts to induced pluripotent stem cells," Nature, vol. 458, no. 7239, pp. 766-770, 2009.

[37] H. Zhou, S. Wu, J. Y. Joo et al., "Generation of induced pluripotent stem cells using recombinant proteins," Cell Stem Cell, vol. 4, pp. 381-384, 2009.

[38] J. Yu, K. Hu, K. Smuga-Otto et al., "Human induced pluripotent stem cells free of vector and transgene sequences," Science, vol. 324, no. 5928, pp. 797-801, 2009.

[39] S. G. M. Piccirillo, B. A. Reynolds, N. Zanetti et al., "Bone morphogenetic proteins inhibit the tumorigenic potential of human brain tumour-initiating cells," Nature, vol. 444, no. 7120, pp. 761-765, 2006.

[40] I. Nakano, K. Saigusa, and H. I. Kornblum, "BMPing off glioma stem cells," Cancer Cell, vol. 13, no. 1, pp. 3-4, 2008.

[41] S. H. Stricker, A. Feber, K. M. Kurian et al., "Direct reprogramming of the glioblastoma epigenome restores developmental potential but does not efficiently suppress proliferation," Cell Stem Cell. In press. 


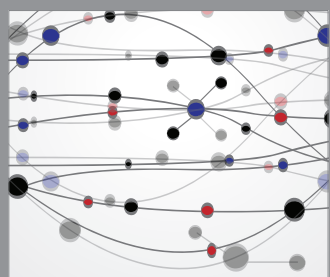

The Scientific World Journal
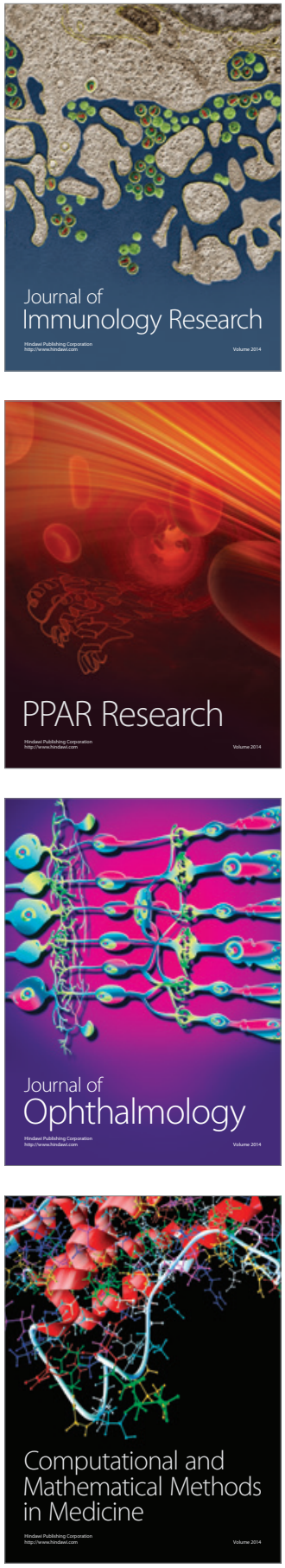

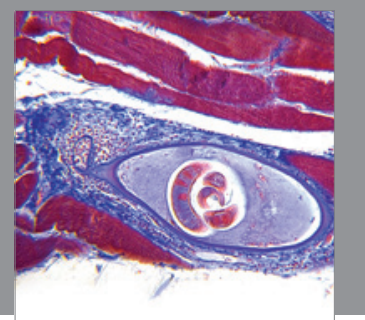

Gastroenterology

Research and Practice
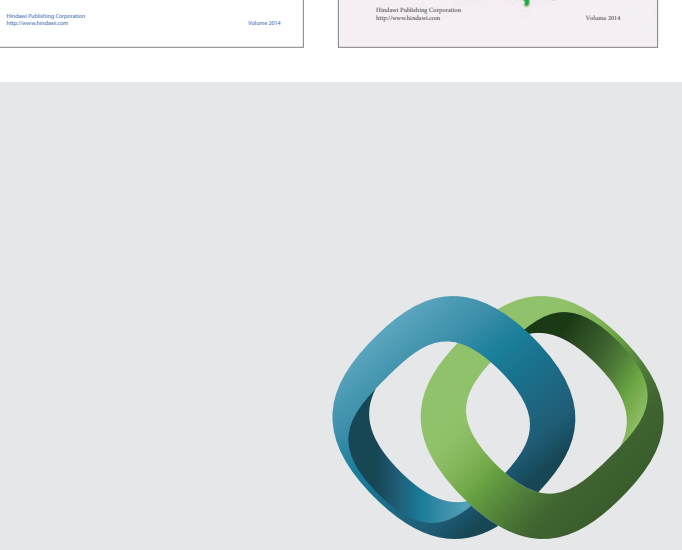

\section{Hindawi}

Submit your manuscripts at

http://www.hindawi.com
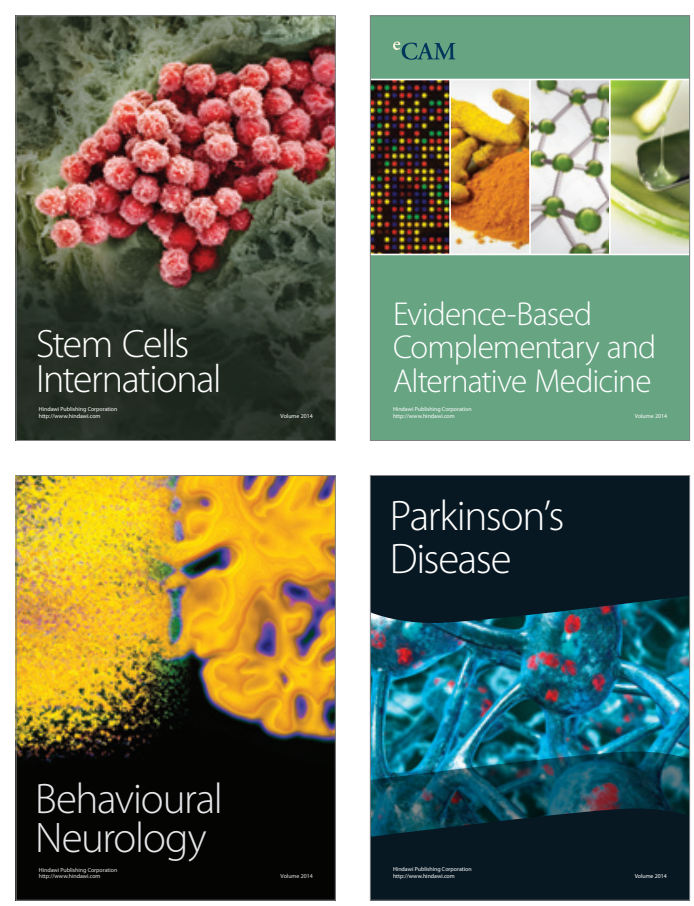

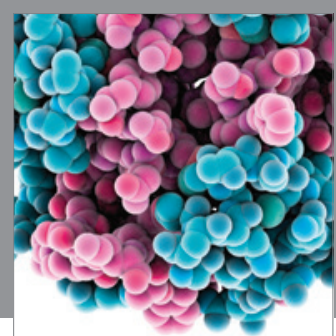

Journal of
Diabetes Research

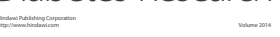

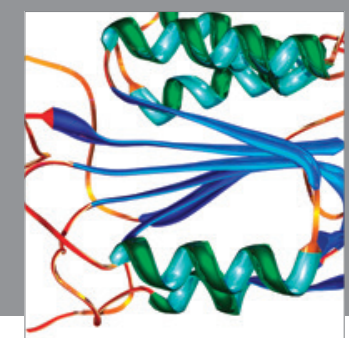

Disease Markers
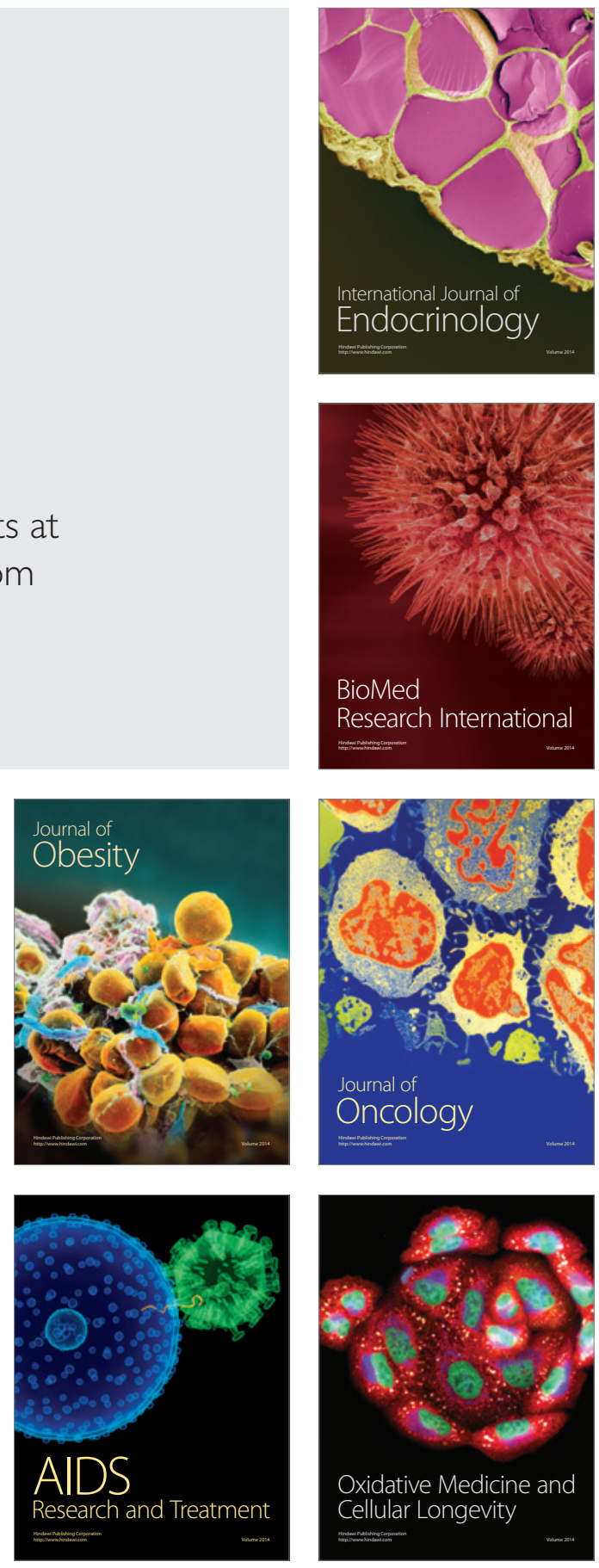